\title{
IMPACT OF COVID-19 ON PHARMACY STUDENTS IN INDIA
}

Nancy Goel ${ }^{1}$, Irfanul Haque ${ }^{2}$, Sarita Jangra Bhyan ${ }^{3}$, Aashi Jain ${ }^{4}$, Amrita Kumari ${ }^{5}$, Besty Thomas $^{6}$, Kulsoom Hamid ${ }^{7}$, M. Sreelakshmi ${ }^{8}$, Rashi Chauhan ${ }^{9}$

1. Pharm D Intern Students, Department of Pharmacy Practice, Teerthanker Mahaveer College of Pharmacy, TMU, Moradabad, Uttar Pradesh, India. Email: nancygoel1254@gmail.com

2. Head of Department, Department of Clinical Pharmacology Jaypee Hospital, Noida, Uttar Pradesh, India.

3. Internship Coordinator, Assistant Professor, Department of Pharmacy Practice, Teerthanker Mahaveer College of Pharmacy, TMU, Moradabad, Uttar Pradesh, India.

4. Pharm D Intern Students, Department of Pharmacy Practice, Teerthanker Mahaveer College of Pharmacy, TMU, Moradabad, Uttar Pradesh, India.

5. Pharm D Intern Students, Department of Pharmacy Practice, Teerthanker Mahaveer College of Pharmacy, TMU, Moradabad, Uttar Pradesh, India. Email:

6. Pharm D Intern Students, Department of Pharmacy Practice, Teerthanker Mahaveer College of Pharmacy, TMU, Moradabad, Uttar Pradesh, India.

7. Pharm D Intern Students, Department of Pharmacy Practice, Teerthanker Mahaveer College of Pharmacy, TMU, Moradabad, Uttar Pradesh, India.

8. Pharm D Intern Students, Department of Pharmacy Practice, Teerthanker Mahaveer College of Pharmacy, TMU, Moradabad, Uttar Pradesh, India.

9. Pharm D Intern Students, Department of Pharmacy Practice, Teerthanker Mahaveer College of Pharmacy, TMU, Moradabad, Uttar Pradesh, India.

\section{*Corresponding author:}

Nancy Goel

Pharm D Intern Students, Department of Pharmacy Practice, Teerthanker Mahaveer College of Pharmacy, TMU, Moradabad, Uttar Pradesh, India.

Email: nancygoel1254@gmail.com

Mobile no: +91 8476853735 


\begin{abstract}
The world is suffering from the Coronavirus pandemic and is undergoing some drastic changes in day to day lives. The survey was conducted to analyze the situation of Pharmacy students in India. What are the types of challenges being faced by them during this lockdown due to the Pandemic COVID-19 and how are they getting adapted to the situations? A cross sectional survey was conducted via snowball sampling technique in which 226 participants submitted their response. The chief issue of concern to students was the change in the study pattern which has made the process much difficult for both the faculties and students. Online examination was also be reported as a point of concern. The normal life that we used to have is not acceptable in today's scenario, hence, the institutions have to make the students more comfortable and adaptable towards the online studies and make the most out of it.
\end{abstract}

Keywords: Coronavirus, Lockdown, Pandemic, Survey, Students, WHO. 


\section{INTRODUCTION}

Severe Acute Respiratory Syndrome CoV-2 caused the novel Coronavirus disease which was firstly diagnosed in Wuhan, Hubei Province, now influencing whole world in such a short period of time (Lu R et al, 2020; WHO.int 2020; Del Rio C et al, 2020). More than 10.2 million cases of COVID-19 were introduced by June 30, 2020 from which 5,06,236 cases resulted in death worldwide and if taking account of the cases in India, there have been 5,67,536 from which 16,904 resulted in death cases (Worldometers 2020). Global imperative efforts were called by the WHO to prevent the rapid rise in the cases of COVID-19 and stated it as a public health emergency of International concern (WHO 2019-nCoV, 2020). SARS-CoV-2 have an outward edge of envelope proteins looking like crown, which has a phylogenetic genome resemblance with exceptionally pathogenic and poisonous with other known coronavirus i.e. SARS-CoV-1 (2003) and MERS-CoV (2012) (Chan-Yeung et al, 2003; Burrell et al, p.437-446; WHO. Coronavirus infection, 2020; WHO-MERS CoV, 2020). The factor which is proving this virus to be very prompt and unpredictable is its basic reproduction rate which seems to be $\mathrm{R}_{0}=2.2$ or more upto 6 according to some studies (Zhou P et al, 2020; Riou J et al, 2020; J.T. Wu et al, 2020 p.689-697)

India was expected to face a huge pile of challenges and a great risk by the widely spreading pandemic of COVID-19 because of its huge socio-cultural diversity, economic disparity and health inequalities. The steps like the immediate enforcement of the lockdown which was enormously helpful in breaking the chain of transmission of the COVID-19 and was also applauded by the WHO (The Lancet, 2020; Economic times. COVID-19, 2020). As India is the second largest internet user country in the world with more than 560 million from 1.37 billion aggregate population (Statista.com, 2020). Transmission of misinformation is as lethal as the transmission of virus, and in India as a country of second highest internet users, the spread of 
misinformation like washing the nose with saline, spraying of alcohol and chlorine on vehicles and people or $5 \mathrm{G}$ mobile network blocking the spread of virus could mislead and confuse the people (S Helen et al, 2020)

As we are aware about the outbreak of the pandemic COVID-19 and the steps taken by the Indian Government for breaking the chain of the spread and controlling the cases to the possible minimum numbers. For this the most important step was the Lockdown of more than 2 months and still going on in a different way. This survey tells us about the situations of the Pharmacy students in India and how their studies and life got affected by this change of settings in the academic learning pattern. We have gathered most of the important factors about how they are getting affected and in which way: either in a positive or negative manner.

The main agenda of the survey is also to look after the mental situation of the students as changes in the pattern of study and life and some students residing alone in a room can be kind of lethal at times. Depression and anxiety both are common mental disorders and depression is the fourth leading cause of morbidity and has a prevalence of $10-44 \%$ in the developing countries. Anxiety and depression symptoms accounts higher frequency in University students and they are disclosed to multiple stressors unique to this developmental period (Z Faruk, 2020).

Following advisories being issued by the Ministry of Health and Family Welfare, Government of India and having the correct information about the precautions to be taken and current scenario are the most important factor in preventing the spread of the virus locally. 


\section{Materials and Methods}

This is a cross sectional survey conducted via snowball sampling technique. The survey was conducted for 2 months in India. As the lockdown was going on, the survey was taken through online sources. The questionnaire was developed with the reference of http://gui2de.georgetown.edu/covid-19/ (Hamza A et al, 2020) after taking legal permission from them via mail. The questionnaire developed consists of demographic questions and 16 other questions. The questions included in this questionnaire were both open as well as close ended. Google forms was used to develop the questionnaire. This study was conducted to understand the situation of the Pharmacy Students during the lockdown period. What are the kind of difficulties faced by them in the academics and how are they getting through this period and what steps have been taken by their respective Institutions about their studies and examinations. The questionnaire was made available to the participants through emails and social networking sites such as LinkedIn, Whatsapp, Facebook and Instagram. All the participants were provided with their consent form and declaration the confidentiality and anonymity. The participants who took part in this survey were the Pharmacy College students who can understand the survey and content asked in it. Overall the questionnaire was filled up by 226 participants from which 219 participants gave their consent for this survey and other 07 participants denied the consent. Convenient sampling method was being used for data collection and the distribution responses were explained in frequency and percentage of their outcomes. Finally the data was tabulated in the excel sheet and concluded as the result. 


\section{RESULT}

The survey was attempted by 226 participants. The mean age of the participants was calculated to be $22.37 \pm 1.74$ years. Out of 226 participants 219 participants have given their consent to fill up the questionnaire and other 7 participants denied their consent. 49.77\% (109) of the participants were female and $50.22 \%$ (110) of the participants were male. All the participants who were provided with the questionnaire were from Pharmacy background. The big percentage of the students who participated were pursuing Pharm D that accounted $81 \%$ of the total participants. Other participants who took part in the survey were pursuing B.Pharm (10\%), M.Pharm (04\%), D.Pharm (03\%) and others $(02 \%)$. The questionnaire was tried to cover as many regions as we could for better survey purpose through different social sites such as LinkedIn, Whatsapp, Instagram, Facebook and Emails. Most of the participants who took part in the survey were observed to be from Uttar Pradesh (27.90\%) followed by Kerala (16\%), Tamil Nadu (8.70\%) and Madhya Pradesh $(7.80 \%)$ and the least responses were observed from states like Assam and Chattisgarh as shown in Table no.1.

\section{a. Has your Institution moved to Virtual instructions?}

According to the result of the survey, most of the students voted in the favour of their Institutions that the Institutions moved accordingly as the virtual instructions that were given by the Government and proceeded in that direction as shown in figure no.1(a).

\section{b. Has your institution closed its student dormitories?}

As per the results of survey $85.12 \%$ of the students stated that the dormitories were being closed by their respective Institutions and the students were sent back to their home while the rest of the 
students (14.88\%) stated that the dormitories of their respective Institutions were still open and the students were allowed to stay there as shown in the figure no.1(b).

\section{c. Where are you staying currently?}

According to the responses we received around $69 \%$ of the students were not staying in the city where their Institution is located but staying in different city or town while around $28 \%$ of the students were living outside their Institutional campus but in same city and other $3.20 \%$ students were still staying in their Institutional campus as shown in figure no.1(c).

\section{d. Is the residence a stable permanent address?}

According to the result of the survey it was observed that $87 \%$ of the participants were living in a stable permanent address as shown in figure no.1(d).

\section{e. Currently Living or Staying with?}

According to the responses we received $92 \%$ of the participants were residing with their families while $06 \%$ of the participants were residing with their roommates and the other $02 \%$ of the participants were residing alone. Hence, combining the participants living on their own and with roommates, $08 \%$ of the participants were staying away from their families as shown in figure no.2(e).

\section{f. Comparison to the life before COVID-19}

Based on the responses of the survey, $30 \%$ of the participants feel that healthcare access is same in this pandemic as before whereas $22.58 \%$ of the participants feel it has been better during this pandemic and $30.12 \%$ of the participants feel it gotten worse than before. If talking about the Internet access to them, $46.17 \%$ of the participants it has not changed and remained as it is whereas $27 \%$ of them feel it has been getting worse than before. One of the important question of 
the survey was to know about how the ability to pursue their study is getting affected and the participants responded as most of them (68.03\%) thinks that pursuing studies has got worse than before and the students are facing many problems studying online or studying regularly like the way they are supposed to be during this pandemic while $7 \%$ of the participants thinks that the ability to pursue studies have gotten better during this pandemic. As the lockdown in the whole country was going on and everyone is asked to maintain social distancing, 59\% of the participants feel that the ability to socialize has become much worse than before it used to be. As getting locked in a small space is not an easy thing to do especially in a place like India where people love to go out so it obviously must be difficult to stay well mentally being restricted in all the normal things we used to do whole our lives. According to the recorded responses, $44 \%$ of the participants feel that the overall psychological has gotten much worse than before and people are facing psychologically ill during this phase, whereas $26 \%$ of the participants feel that nothing has changed and the psychological health of people is same as before and the other $14 \%$ feel that this lockdown phase has bring some betterment to the psychological health of the people leading to a better life as shown in figure no.2(f).

\section{g. Any change experienced in the semester}

Based on the responses received by the participants it was concluded that expenditure, financial aids and debt of around half of the participants remained the same in this semester when compared to the past ones as shown in figure no.2(g).

\section{h. Decision to close campus and move to online classes}

According to the responses received in the survey around $79 \%$ of the participants stated that their Institution took the required steps for closing the campus and moving the classes to the online platform to swiftly or at least timely and prudently whereas $21 \%$ of the participants stated that 
their Institution was too slow in making the adjustments according to the need of time and were very slow in closing the campus and moving the classes on the online platform as shown in figure no.3(h).

\section{i. Do you have mental pressure with promoting of the students with online exam?}

This is one of the most important issues which has to be noticed because the lockdown has brought a lot of psychological illness in the youngsters such as anxiety and depression. The concept of online exam for the promotion of the students has a part to affect the student's mental status as it is a new platform for them to give examination and many other factors to go on. According to the result of our survey responses we have found that $24 \%$ of the participants were feeling extreme level of mental pressure because of this online examination while $46 \%$ of the participants feel that they are not under extreme but they still feel a moderate amount of pressure in their head. The other $30 \%$ of the participants are alright with the online examination concept are not under so much of pressure as shown in figure no.3(i).

\section{j. Has your Industry visit suffered?}

As this survey was for the Pharmacy students, B.Pharm and M.Pharm students have got their scheduled Industry visits especially for the last semester students. $55 \%$ of the participants stated that there Industry visit schedule has been affected by the lockdown as shown in figure no.3(j).

\section{k. Has your Ward round participation been affected?}

The students of Pharm D use to have the hospital ward rounds as their curriculum activity and their ward round participation has definitely got disturbed by the lockdown and increase of COVID-19 patients in the hospital. $66 \%$ of the participants stated that their ward round participation has got affected due to the ongoing pandemic as shown in figure no.3(k). 


\section{l. Has your ongoing project got affected?}

As a student, they have project works going on in the semesters which has to be submitted for the promotion of the students to the next semester. $69 \%$ of the participants stated that their project work has been affected due to the lockdown as shown in figure no.4(l).

\section{m. Compared to before COVID-19, how do you feel in general?}

The pandemic COVID-19 has made a huge difference in people's lifestyle. The situation has become quite alarming and everyone needs to take precautions in their day to day life and nothing is same anymore. According to our study most of the participants feel that all the present and future plans are going to get much more worse from what they had actually planned as shown in figure no.4(m). 


\section{DISCUSSION}

The huge majority of 37.4 million students (Education and Training Centre in India, 2020) and their faculties of Universities in India have been immediately forced to replace their physical classes with the online class formats. In order to understand the impact of COVID-19 in the life of the Pharmacy students, we surveyed 226 students from different Pharmacy Colleges of India and tried to know about the situations they are facing in their academics pattern and otherwise due to this pandemic. The online class format is completely a new experience for the faculty members as well as the students. Both of them are not prepared or trained nor used to this kind of virtual learning. This also has declined the potential learning of the students. According to our study, it has been observed that most of the Pharmacy students are also getting affected because of the online studies that they have to acquire because of the closed campus. It is critical to find the ways both the students and teacher feels better on the concept of online learning as this is the need of the hour and has to be continued for a period of time until this pandemic is reduced to a controllable levels. So as we have to get used to the online learning, there are few steps which might be taken such as having some workshops and webinars of both the students and teacher making them learn and comfortable to study online. The psychological barrier plays a big role in studying and hence, the psychological barrier has to be removed as the first step towards better online learning and better ways of teaching and grasping has to be proposed to them for better results. Current literature also indicates that the first few weeks of the new academic life will play a very significant role in the lives of the students and faculty so it is kind of important to sense the need of the hour and try and start from the basics of learning rather than rushing it up into it. As according to our study many students are facing a situation where they feel that the instructor is not putting efforts in their respective online classes. These could be the results if the basics of the online learning and teaching are not clear enough and hence, it has to be resolved as quickly 
as possible. Participation, engagement and satisfaction of the student in an online class are the key outcomes for which a teacher has to work hard for by properly giving their social presence and attentiveness in the online class (Rickley $\mathrm{M}$ et al, 2020). Our study also suggests that many of the students were having good opinions on the work done by their Institutions by closing the institutions and beginning the process of online studies as soon as the virtual orders were released, which is kind of important that the strong connection between the students and the Institution be in well mannered way (Misirlis N et al, 2020; Huckins F.J et al, 2020). The other problem which the students were facing according to our study was the criteria of the online examinations that they were asked to pass for getting promoted. The students were facing mental pressure because of the online examinations which has many factors to be supported as the students do not have enough study material available at the place they are staying during this pandemic, every student do not have proper Internet access to be present in the examinations, the online classes they took during this lockdown were not beneficial enough and they were not able to grasp on to what is being taught in the online class etc. According to our study most of the students seemed to be staying at their home whereas some students were also still residing in their Institutional campus, which has immensely affected their Industrial visits and Ward rounds practice. All these activities has been abandoned since the lockdown was initiated and will remain abandoned until the lockdown gets over and things get normal as they were. This is also affecting the practical knowledge of the students which is quite important in the curriculum. The project work of the students like final year students have their thesis work to perform and other junior students also have projects to perform and all that has also been affected due to this pandemic. The other major issue that we came across this study was the students complaining about the Institutions for demanding the fees such as Examination fee which was very difficult for a middle class family to submit in such a time where their salary was not even credited to 
them properly so it is a suggestion and it should be compulsory that no Institution demand fees from the students and if they do they should provide relaxation to the students who are not able to submit their fees during this period. A study shows that on an average almost $31 \%$ of working students suffers from decrease in their wages and 37\% nosedive in weekly hour work (Aucejo E.M et al, 2020). The situation is not going to change for the positive in nearby, so it is better to get prepared strongly from the basics and try and implement the new type of life that we are living during this phase of pandemic for the safety and betterment of us and everybody around us.

\section{LIMITATIONS-}

The study we performed had some limitations. To start with, our sample was small, though already much bigger compared to the previous similar studies. Limited sources due to pandemic lockdown also caused some difficulties in our survey. So, we had to run our survey only for 60 days and could only send one reminder to the students. This is the reason that we acquired only a $23.6 \%$ response rate (226 responses from 928 students we sent to). We also had limited reach to the participants because of the lockdown, personal interaction could not be done and responses were collected by sending the questionnaire through social media sites and email which made the survey not as noticeable as we wanted and could be the reason for the decline in responses. Additionally we did not collect the information if the participants were infected or not or any family member or neighbour was infected or not and the major source used by students to obtain information about COVID-19 which could be improved in further studies. 


\section{CONCLUSION}

From the responses we received from the Pharmacy students it could be concluded that most of the students are facing problem with this instant change in the way of teaching from physical presence teaching to the online teaching. Some students also stated that they do not have internet access at the place they are staying which is making it worse for them to attend classes regularly and learn from it. Some serious problems also appears for those students who are staying away from their families in such tough time as they have to do a lot of tasks on their own and have a big pack of pressure on them and living alone increases the intensity of pressure only. Students also kind of had problem in dealing with the online examination because of many factors such as lack of internet access, lack of study material etc. The project of the students are also left undone because of the lockdown and also the practical studies such as Industry visit and Ward rounds are also not being performed as they are not at the Institution. All in all the students and faculty both seems to have a lot of problems due to the lockdown and change the process of learning.

As a solution, rushing is not an option. Just keeping in mind to complete the syllabus and not getting the outcome from it do not help anyone. If the teacher teaches it has to be taught to the student. For this to get happened, it is necessary to concentrate on the basics of the learning and faculties and students both must be given proper guidance via webinars to make them psychologically accept the fact what is going around and we have to accept that this is the new normal for at least few months from now. Once it is psychologically accepted it will be much easier for everyone to get along it.

\section{ACKNOWLEDGEMENT-}

The author would like to thank the institution and the colleagues for the guidance and constant supervision as well as for providing necessary information regarding the project. 


\section{REFERENCES}

1. Lu R, Zhao X, Li J, Niu P, Yang B, Wu H, et al. (2020). Genomic characterisation and epidemiology of 2019 novel coronavirus: implications for virus origins and receptor binding. Lancet, 395(10224), 565-74.

2. WHO.int. Naming the coronavirus disease (COVID-19) and the virus that causes it, c2020 [Accessed on 2020 June 28].

Available from: https://www.who.int/emergencies/diseases/novel-coronavirus-2019

3. Del Rio C, Malani PN. (2020). 2019 novel coronavirus-important information for clinicians. JAMA, 323

4. Worldometers . COVID-19 Coronavirus Pandemic. Worldometers. [Accessed on 2020 June 29]

Available from : https://www.worldmeters.info/coronavirus

5. World Health Organization. 2019-nCoV outbreak is an emergency of international concern. 2020. [Accessed on 2020 June 29]

Available from: http://www.euro.who.int/en/healthtopics/emergencies/pages/news/new s/2020/01/2019-ncov-outbreak-is-an-emergencyof-international-concern

6. Chan-Yeung M, Xu RH.(2003). SARS: epidemiology. Respirology, 8, 9-14.

7. Burrell, C.J., Howard, C.R., Murphy, F.A. Coronaviruses. Fenner and White's Medical Virology (Fifth Edition). Academic Press, London, pp.437-446.

Available from: https://doi.org/10.1016/B978-0-12375156-0.00031-X.

8. WHO. Coronavirus Infections: Disease Outbreak News WHO [Accessed on 2020 June 29] Available from- https://www.who.int/emergencies/diseases/novel-coronavirus-2019 
9. WHO- Middle East respiratory syndrome coronavirus (MERS-CoV)-Saudi Arabia [Accessed on 2020 June 29]

Available from: http://www.who.int/csr/don/25-july-2016-mers-saudi-arabia/en/

10. Zhou p, Yang Xl, Wang Xg, hu B, Zhang 1, Zhang W.(2020). Discovery of a novel coronavirus associated with the recent pneumonia outbreak in humans and its potential bat origin. Nature.

Available from: https:// doi.org/10.1038/s41586-020-2012-7.

11. Riou J, Althaus CL.(2020). Pattern of early human-to-human transmission of Wuhan 2019 novel coronavirus (2019-nCoV), December 2019 to January 2020. Euro Surveill, 25(4).

12. J.T. Wu, K. Leung, G.M. Leung. (2020). Nowcasting and forecasting the potential domestic and international spread of the 2019-nCoV outbreak originating in Wuhan, China: a modelling study Lancet, 395 (10225), p.689-697

13. The Lancet. India under COVID-19 lockdown .2020; 395 (10233), pp-131

Available from-https://www.thelancet.com/journals/lancet/article/PIIS0140-6736(20)30938-7

14. Economic times. COVID-19: Health ministry comes out with cluster containment strategy [Accessed on 2020 April 28]

Available from- https://economictimes.indiatimes.com/news/politics-and-nation/covid-19-healthministry-comes-out-with-cluster-containmentstrategy/articleshow/74984608.cms

15. Statista.com. Internet usage in India - Statistics \& Facts. [Accessed on 2020 June 29]. Available from: https://bit.ly/2VTobEi

16. S Helen. Hunting down the rumours of COVID-19 [Accessed on 2020 June 29] Available from- https://www.nationalobserver.com/2020/04/11/features/huntingdownrumours-covid-19

17. Z Faruk. COVID-19: Infodemic spreads faster than pandemic [Accessed on 2020 June 29] 
Available from- https://www.aa.com.tr/en/latest-on-coronavirus-outbreak/covid-19-infodemic spreads-faster-than-pandemic/1786381

18. Hamza A, Das J, Daniels B \& Leydier B. (2020). Covid-19 Student impact survey. Georgetown University Initative on Innovation, Development and Evaluation.

Available on: https://gui2de.georgetown.edu/covid-19/

19. Education and Training Centre in India. IBEF. [Accessed on 2020 July $1^{\text {st }}$ ].

Available on: https://bit.ly/3f7g9PC

20. Rickley M \& Kemp P. (2020). The effect of video lecture design and production quality on student outcomes: A quasi-experiment with implications for online teaching during the COVID-19 pandemic. SSRN 3594531.

21. Misirlis N, Zwaan M.H \& Weber D. (2020). International students' loneliness, depression and stress levels in COVID-19 crisis. The role of social media and host university. arXiv.org > cs > arXiv:2005.12806.

22. Huckins F.J, daSilva A.W, Wang W, Hedlund E, Rogers C, Wu J, et al. (2020). Mental health and behavior of college students during the early phases of the COVID-19 pandemic: Longitudinal smartphone and ecological momentary assessment study. J Med Internet Res, 22(6).

23. Aucejo E.M, French J.F, Araya M.P.U \& Zafar B. (2020). The impact of COVID-19 on student experiences and expectations: Evidences from a survey. National Bureau of Economic Research. 


\section{TABLES AND FIGURES}

Table No.I. Sociodemographic details of Pharmacy Students

\begin{tabular}{|c|c|c|}
\hline Characteristics & $\begin{array}{l}\text { Participants } \\
\text { (Frequency 'n') }\end{array}$ & $\begin{array}{l}\text { Participants } \\
\text { (Percentage }{ }^{6 \%} \%^{\prime} \text { ) }\end{array}$ \\
\hline \multicolumn{3}{|l|}{ Sex } \\
\hline Male & 110 & 50.22 \\
\hline Female & 109 & 49.77 \\
\hline \multicolumn{3}{|c|}{ Educational Qualification } \\
\hline Pharm.D & 178 & 81 \\
\hline B.Pharm & 9 & 10 \\
\hline M.Pharm & 21 & 04 \\
\hline D.Pharm & 7 & 03 \\
\hline Other & 4 & 02 \\
\hline
\end{tabular}




\begin{tabular}{|c|c|c|}
\hline Residency & & \\
\hline Uttar Pradesh & 61 & 27.9 \\
\hline Kerala & 35 & 16 \\
\hline Tamil Nadu & 19 & 8.7 \\
\hline Madhya Pradesh & 17 & 7.8 \\
\hline Others (UT) & 13 & 5.9 \\
\hline Haryana & 11 & 5 \\
\hline Uttrakhand & 10 & 4.6 \\
\hline Bihar & 9 & 4.1 \\
\hline Karnataka & 9 & 4.1 \\
\hline Rajasthan & 8 & 3.7 \\
\hline Telangana & 7 & 3.2 \\
\hline Maharashtra & 4 & 1.8 \\
\hline Andhra Pradesh & 4 & 1.8 \\
\hline Tripura & 2 & 0.9 \\
\hline Punjab & 2 & 0.9 \\
\hline Jharkhand & 2 & 0.9 \\
\hline
\end{tabular}




\begin{tabular}{l|l|l}
\hline Gujarat & 2 & 0.9 \\
West Bengal & 2 & 0.9 \\
Assam & 1 & 0.5 \\
Chattisgarh & 1 & 0.5 \\
& & \\
\hline
\end{tabular}




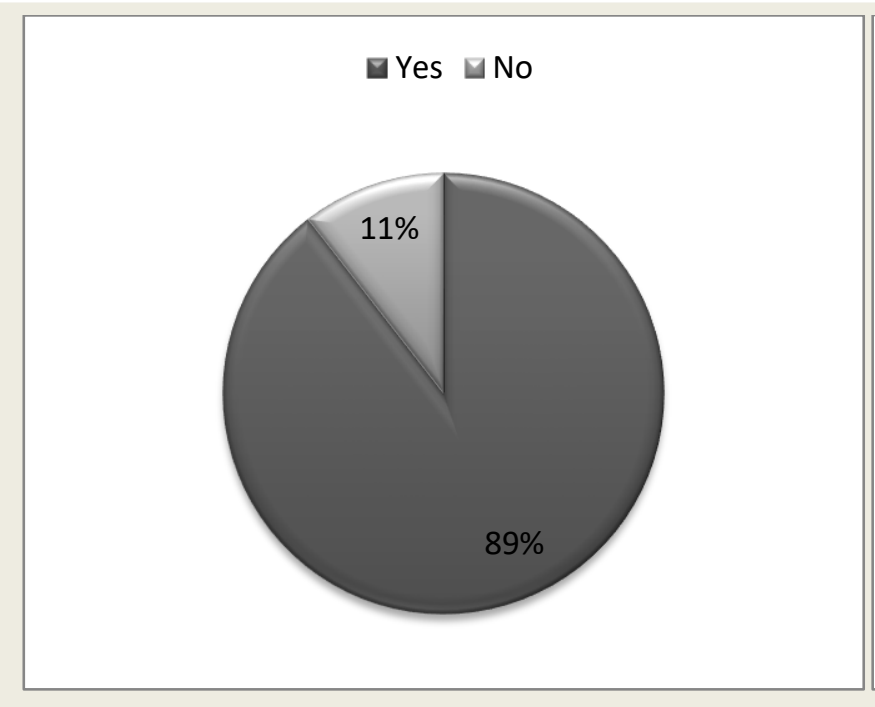

(a)

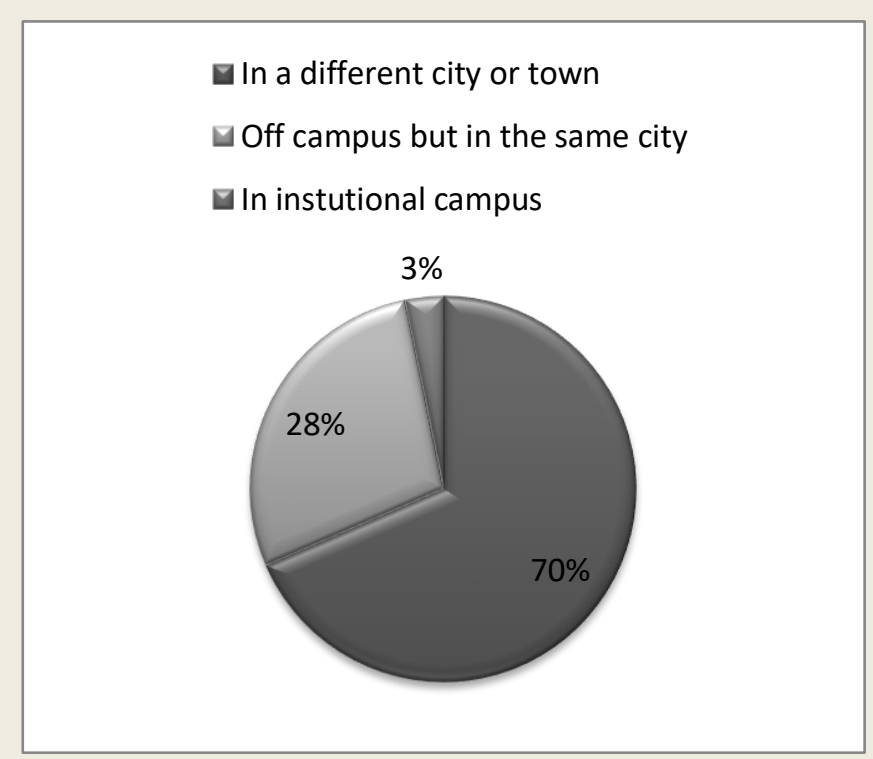

(c)

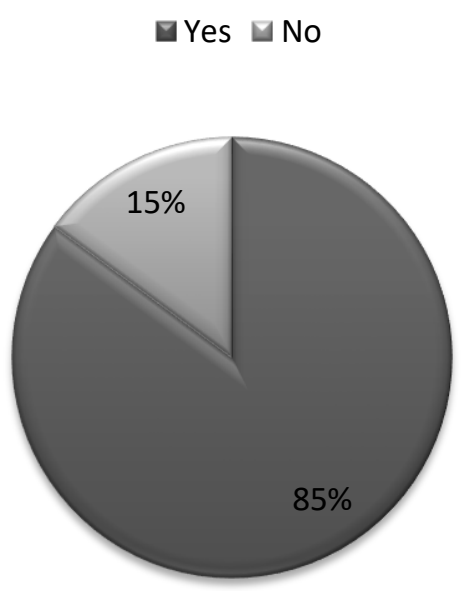

(b)

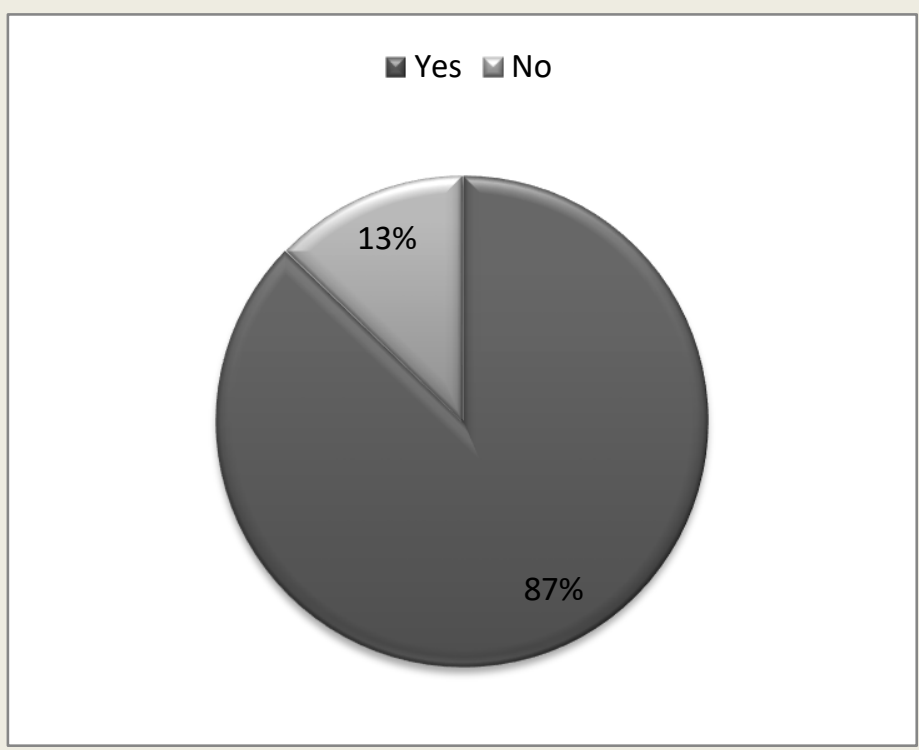

(d)

Figure No.1.

(a) Has your institution moved to virtual instructions?

(b) Has your institution close its student dormitories?

(c) Where are you staying currently?

(d) Is the residence a stable permanent address? 
$\square$ Family $\square$ Roomates $\square$ Alone

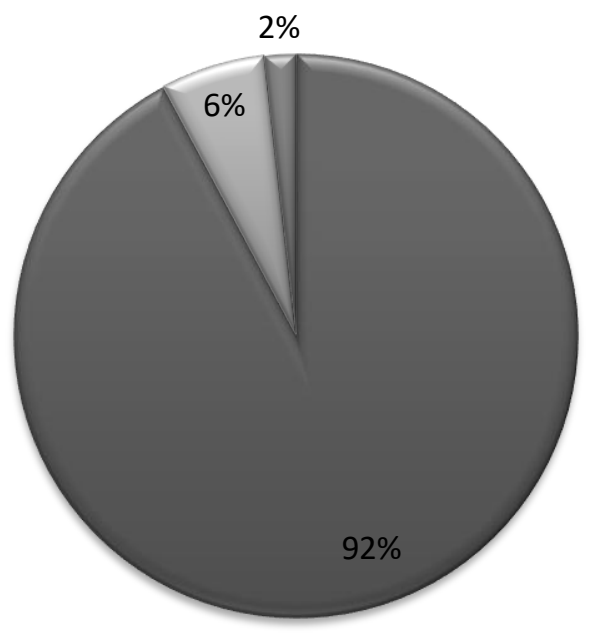

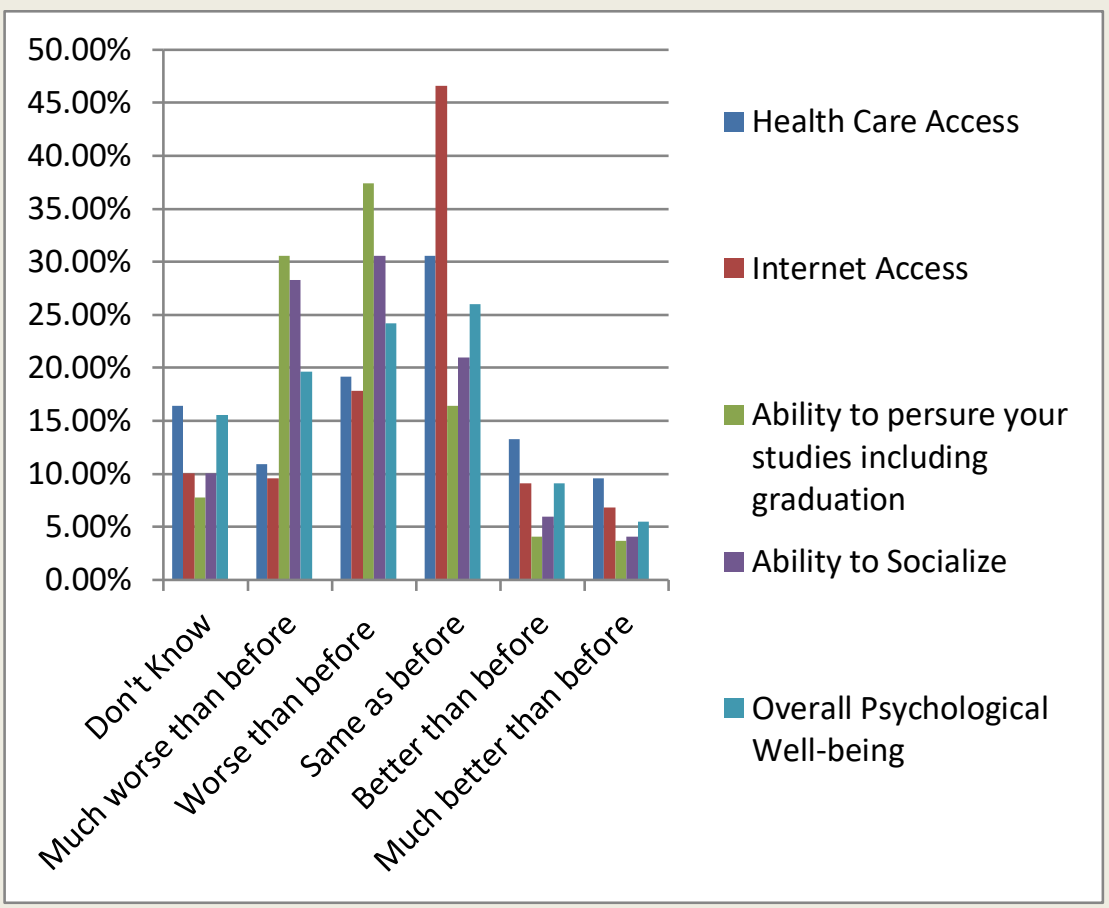

(f)

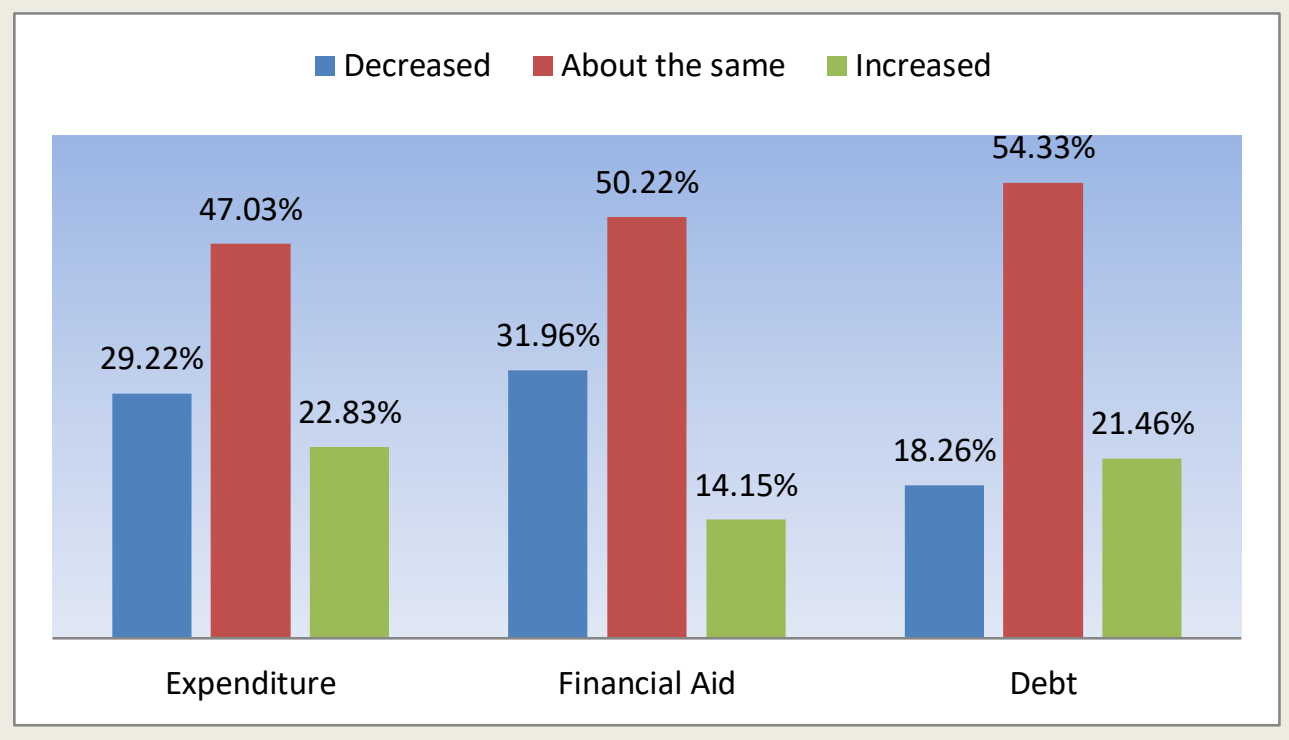

(g)

Figure No.2.

(e) Currently living or staying with?

(f) How would you rank the following in comparison to your life before COVID-19?

(g) Is there any change in the following for you this semester? 


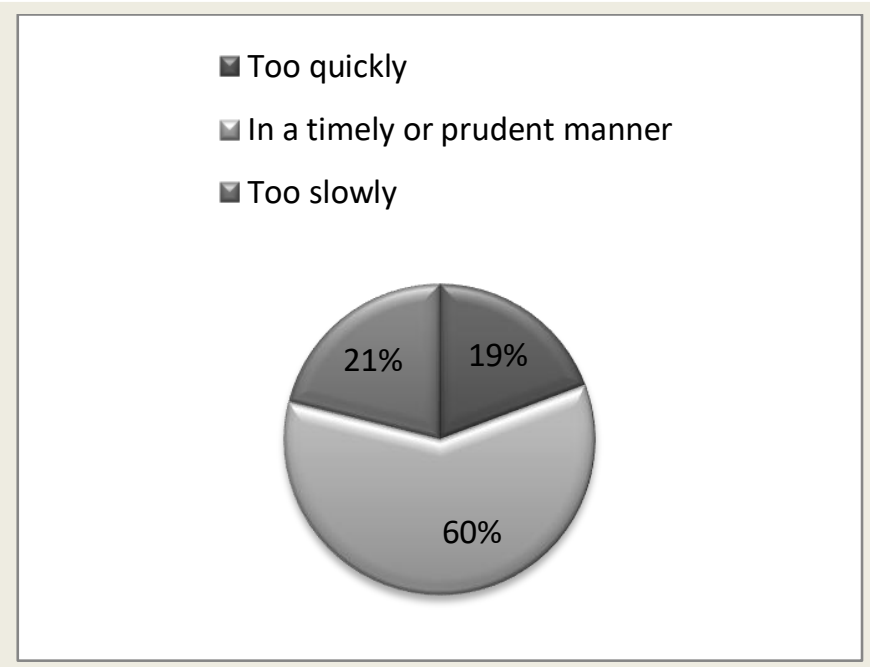

(h)

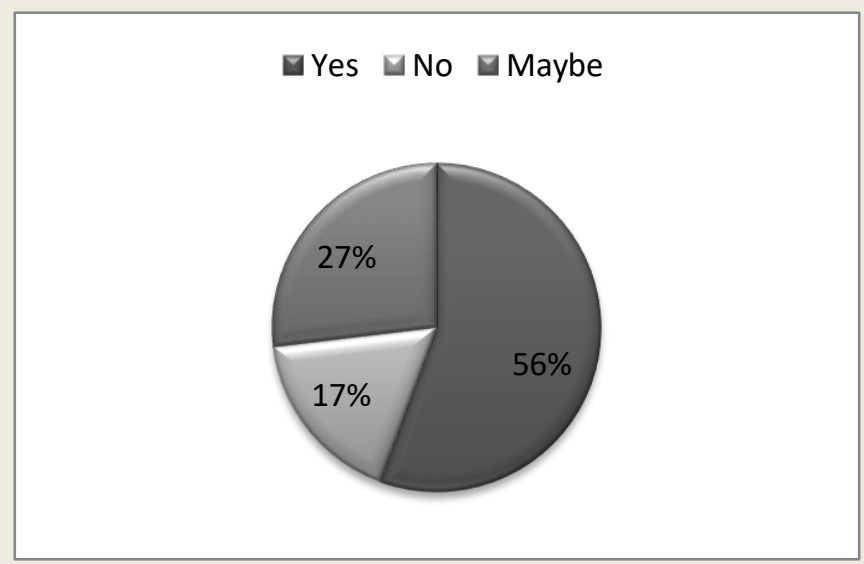

(j)

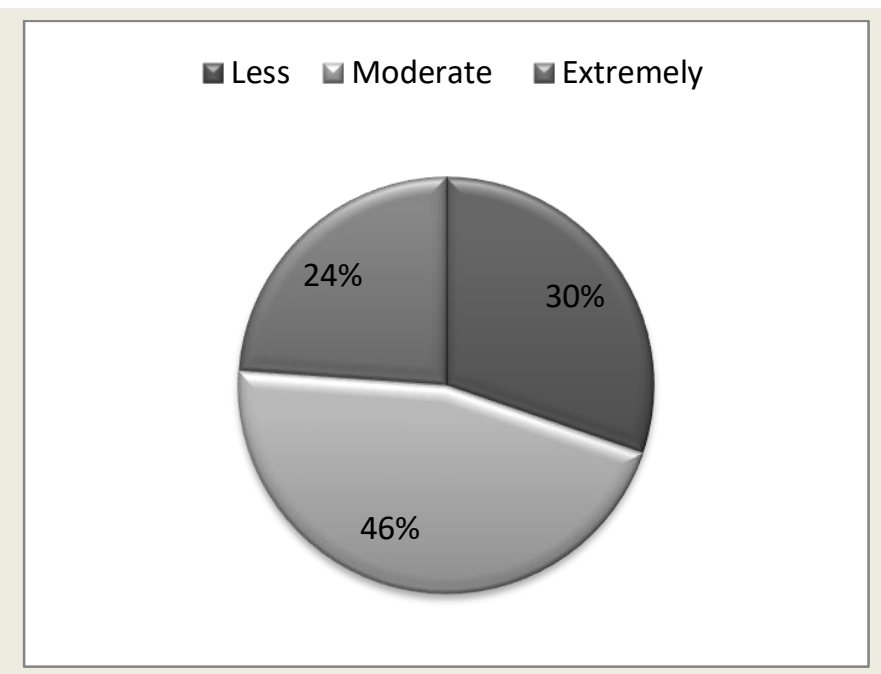

(i)

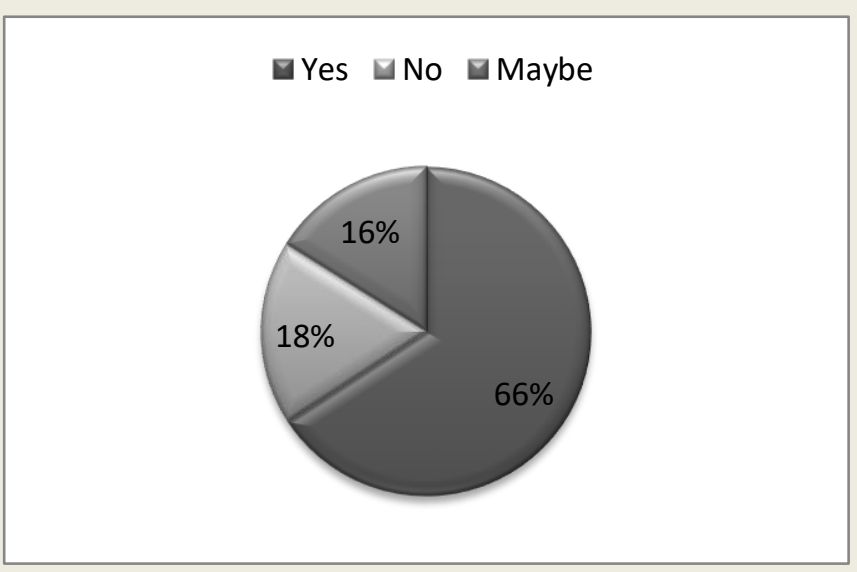

(k)

\section{Figure No.3.}

(h) Decision to close campus and move to online education

(i) Do you have mental pressure with promoting students with online exam?

(j) Has your industry visit suffers?

(k) Has your ward round participation affected? 


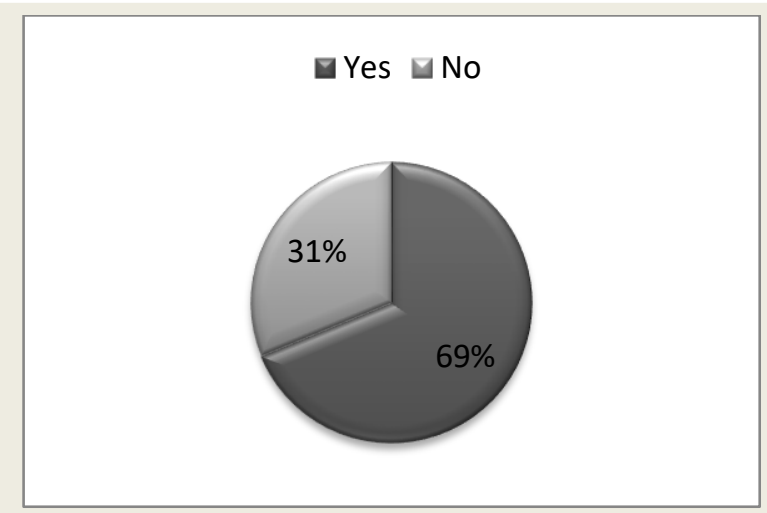

(I)

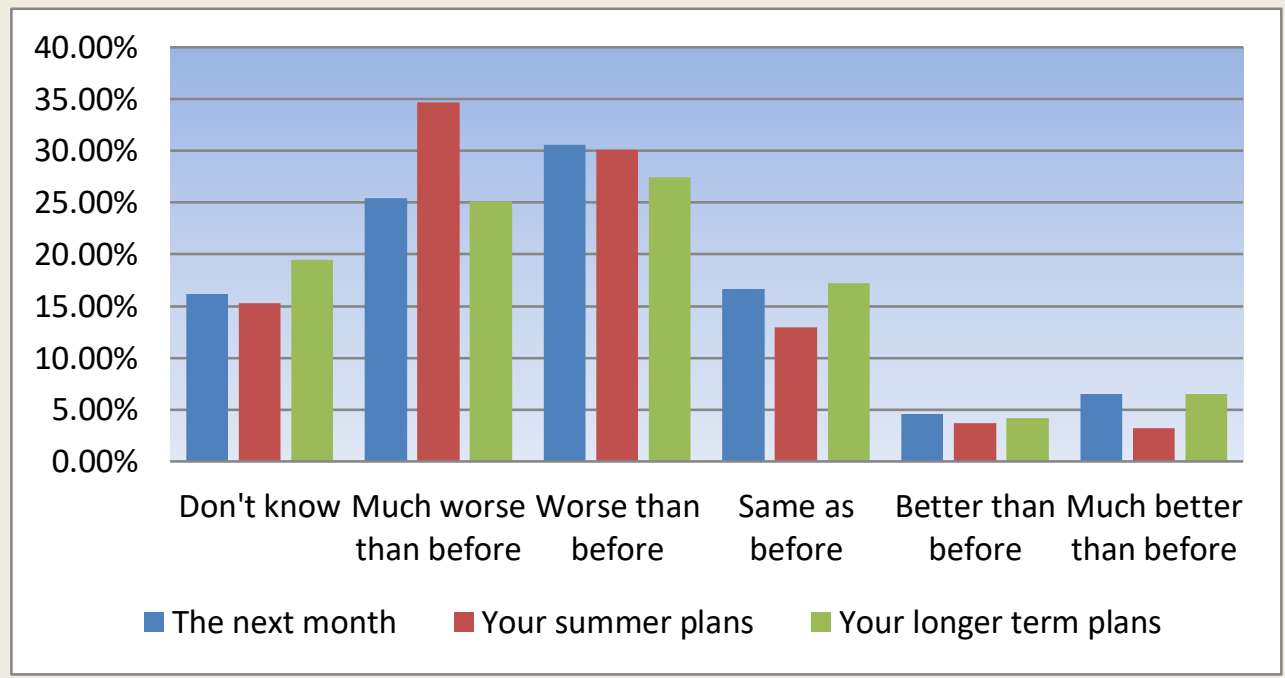

(m)

\section{Figure No.4.}

(1) Has your ongoing project affected?

(m) Compared to life before COVID-19, how do you feel in general? 